\title{
Inflammatory bowel diseases and the general practitioner's role in a region of Central Italy
}

This article was published in the following Dove Press journal:

Clinical and Experimental Gastroenterology

17 April 2010

Number of times this article has been viewed

\author{
Paolo Sossai ${ }^{1,2}$ \\ Fabio Filippetti ${ }^{3}$ \\ Ali Ahmad Muselmani ${ }^{4}$ \\ Giambattista Catalini ${ }^{4}$ \\ 'Department of Medicine, "Enrico \\ Mattei” Hospital, Viale Europa, I-62024 \\ Matelica, Italy; ${ }^{2}$ Center of Clinical \\ Research, Department of Experimental \\ Medicine, University of Camerino, Via \\ M Scalzino, 3, I-62032 Camerino, Italy; \\ ${ }^{3}$ Epidemiological Unit, Marche Region, \\ Via Gentile da Fabriano, 3, I-60I 25 \\ Ancona, Italy; ${ }^{4}$ Department of Surgery, \\ General Hospital, Via Caselle, I-62032 \\ Camerino, Italy
}

Background: Inflammatory bowel diseases (IBD) are a serious burden for both patients and health care providers because of the young age at which they occur and their chronic course.

Aim: The purpose of this study was to assess how general practitioners (GPs) in the area of Camerino-Matelica, Marche (Central Italy) manage their patients with IBD.

Materials and methods: Before providing an educational course about IBD to GPs, we administered a simple questionnaire containing 10 multiple-choice questions, allowing for only one possible answer, to GPs in the target area. After the educational course we administered a satisfaction questionnaire and evaluated the hospitalization rates for IBD in the catchment area in the year following the course.

Results: In our GP sample, $71.8 \%$ indicated that they needed better instruction regarding IBD to enable them to diagnose the conditions given the difficulties posed by nonspecific symptoms and the need to use invasive diagnostic methods such as colonoscopy. Early results after the educational course for GPs indicate a reduced rate of hospitalization for IBD but these data must be confirmed by future research.

Conclusions: If specialists and GPs managed IBD patients more carefully, their patients would probably suffer from fewer relapses and would have a better quality of life, which would be likely to mean considerable cost savings for the public health care system and society in general.

Keywords: inflammatory bowel disease, Crohn's disease, ulcerative colitis, general practitioner

\section{Introduction}

Inflammatory bowel diseases (IBD) are chronic immune-mediated conditions that are associated with a heavy personal and economic burden for patients and health care systems. Ulcerative colitis (UC) and Crohn's disease (CD) are the two main types of IBD. Although their etiologies are unknown, some risk factors have been suggested, including tobacco use (for CD), genetic factors, oral contraceptives, and hormone replacement therapy. ${ }^{1,2}$

A number of European and US epidemiologic studies indicate a substantial increase in the incidence of IBD since World War II, with CD now affecting 6/100,000 and UC 15-20/100,000 of the general population. ${ }^{2}$ An Italian multicenter study indicated a mean annual incidence of 3.4/100,000 for CD and 7.0/100,000 for UC. ${ }^{3}$ The prevalence of IBD has probably been underestimated, especially in its milder forms. ${ }^{4}$ The Italian Association for IBD Patients (AMICI) has calculated that the total number of IBD patients in Italy, as at April 2009, is officially 104,762, with a prevalence of $177 / 100,000$ in the population but, as reported by Rubin et al, the problem is almost
Correspondence: Paolo Sossai Department of Medicine, General Hospital, Viale Comandino, 70 I-61029 Urbino (PU), Italy

Tel +393487383553

Fax +39737783568

Email paolosossai@libero.it 
certainly underestimated given that most studies rely on hospital records. ${ }^{5,6}$

Diagnosis of IBD is often delayed, and the mean interval between symptom onset and diagnosis is $1.5-2.0$ years. It is also difficult to distinguish between CD and UC in clinical practice, because the diagnosis changes within the first two years in $10 \%$ of patients. ${ }^{7-8}$ The fact that these diseases are difficult to diagnose and demand regular monitoring makes the GP's role fundamental both in establishing the primary disease and in dealing with relapses, with a view to reducing hospitalizations, and the related problems and economic costs. Given the generally young age of IBD patients (median age at diagnosis 30 years), the economic costs are not limited to hospital stays, treatments, and tests, but also include the patient's decreased ability to work. The GP's role should be borne in mind when looking at all the factors (medical and economic) involved in these diseases because the GP is the first point of contact for the patient in the health care system. ${ }^{9}$

Rubin et al reported that only $30 \%$ of their patients were under the care of a specialist, whereas about $50 \%$ were dispensed from specialist followup. It is noteworthy that $48.2 \%$ of UC patients and $60.5 \%$ of CD patients in this study were not on treatment for their disease, and about $22 \%$ of patients with extensive colitis (ie, those most in need of cancer screening) were lost to specialist followup. ${ }^{6}$ A UK study by Stone et al confirmed Rubin's findings with regard to the prevalence of IBD and showed that about $32 \%$ of patients were under the care of a GP alone, ${ }^{10}$ reporting that only $65 \%$ of patients had been prescribed 5 -aminosalicylate in the previous six months, and only $42 \%$ of patients adhered to their prescribed therapy. Also noteworthy is that only $69 \%$ of CD patients were given advice on smoking cessation.

Because $30 \%-50 \%$ of IBD patients are under the care of GPs, who as a group do not seem to be well informed about the importance of continuous treatment with 5-aminosalicylate, screening for colon cancer, and the need to advise their patients (especially those with $\mathrm{CD}$ ) to quit smoking, we conducted a brief investigation among local GPs on relevant topics, including timing of appointments, endoscopy, and laboratory followup for IBD patients, and hospitalization rates before a continuing medical education (CME) course.

\section{Patients and methods}

This study was done in a hilly and mountainous area covering 1281.49 square kilometers in the Marche region of Central
Italy, inhabited by about 49,100 people (38.2 people per $\mathrm{km}^{2}$ in December 2005), which is a lower density than the average for the Marche region (147.9 per $\mathrm{km}^{2}$ ). There are 39 GPs serving the area, comprising 33 males and six females, with a mean age of $52.8 \pm 4.3$ years (median 53 years; range $43-$ 64 years). Latest data available for this area identify 95 IBD patients as at 31 December 2004 (Marche Regional Authority database). The prevalence of about $190 / 100,000$ population is fairly evenly distributed throughout the Marche region.

In the Marche region about 6.2/100,000 population/year are hospitalized for $\mathrm{CD}$ (95\% confidence interval [CI]: 6.0-6.4) and 17.7/100,000 for UC (95\% CI: 17.6-17.8) [database 2004-2006]. In the Camerino-Matelica area, 13.3/100,000 population/year (95\% CI: $12.3-14.2$ ) are admitted to hospital for $\mathrm{CD}$ and $23.5 / 100,000$ population/year $(95 \%$ CI: 22.7-24.7) for UC [database 2004-2006]. The above reported data are according to statistics from the last ISTAT (Italian Statistics Institute) census in 1991.

The mean age of patients hospitalized for IBD in our area is similar to the average for the Marche region (45.8 years versus 47.1 years, $P>0.05$ ), as is the gender distribution (55.8\% of males in our target area versus $53.3 \%$ in whole region, $P>0.05$ ), so there is unlikely to be any difference between the type of patient living in our area and those living elsewhere in the Marche region.

In an attempt to improve and coordinate the management of these patients, the Department of Surgery in Camerino and the Department of Medicine in Matelica instituted a CME course for GPs on 25 May 2007. Before starting the course, each GP completed an anonymous multiplechoice questionnaire containing 10 items allowing for only one answer to each question (Table 1). The purpose of this questionnaire was to assess how GPs approached treatment of their IBD patients before they attended the course. Following the course, GPs were asked to fill out an anonymous questionnaire to assess their satisfaction with the course, using a numerical scale of $0-5$. We also verified the rate of hospitalization of IBD patients in both regional (Marche) and local (Camerino-Matelica) hospitals in the year following the course.

\section{Statistical analysis}

The data were analyzed using the Student's t-test for mean comparisons and the Chi-square test for gender comparisons. A $P$ value $<0.05$ was considered to be statistically significant. We used $95 \%$ CI for the hospitalization rates. The Stata $^{\circledR}$ statistical program, (version 10, Statacorps College Station, TX) was used. 
Table I GP questionnaire

I. Have you ever treated or are you presently treating patients with IBD? Yes/No

2. How often do you examine your IBD patients (not just prescribing medicine)?

Every month, every three months, every six months, or once a year.

3. How often do you order laboratory tests for your IBD patients?

Every month, every three months, every six months, or once a year.

4. Do you use the fecal calprotectin test (available at our laboratory) for the diagnosis or follow-up of your IBD patients?

Always, almost always, in about half of my patients, rarely.

5. Do you prescribe probiotics for your UC patients?

Always, almost always, in about half of my patients, rarely.

6. Do you prescribe antibiotics for your CD patients? Always, almost always, in about half of my patients, rarely.

7. If your IBD patient relapses, do you involve the specialist? Always, almost always, in about half of my patients, rarely.

8. If you decide to change your IBD patient's treatment, do you seek advice from a specialist first?

Always, almost always, in about half of my patients, rarely.

9. Do you recommend that your female IBD patients of child-bearing age avoid becoming pregnant? Yes/No

10. Apart from patients requiring followup for carcinoma, how often do you carry out endoscopic examinations? Once a year, once every two years, on disease relapse, rarely.

\section{Results}

Twenty-eight GPs (71.8\% of the total canvassed) answered the questionnaire and attended the CME course. Only one of them had never had an IBD patient. The mean number of IBD patients per GP in our catchment area was 2.4. GPs completed the questionnaire in about five minutes and returned their completed questionnaire before starting the course so that the information provided on the course could not influence their subsequent answers.

The GPs visited their patients with the following timing: monthly $26 \%$ of GPs, every three months $33 \%$, every six months $30 \%$, and every year $11 \%$. Laboratory tests were requested each month by $4 \%$ of GPs, every three months by $22 \%$, every six months by $59 \%$, and every year by $15 \%$; $74 \%$ of GPs did not require determination of calprotectin in patients with IBD and only $15 \%$ of GPs used antibiotics in CD patients. Also, the use of probiotics in UC was limited, with only $37 \%$ of GPs always using them (Table 2 ).

When asked whether they advised female IBD patients of child-bearing age to avoid becoming pregnant, $74 \%$ of the
Table 2 Results of GP questionnaire

\begin{tabular}{llll}
\hline & Always & $\begin{array}{l}\text { In about 50\% } \\
\text { of cases }\end{array}$ & Rarely \\
\hline Calprotectin analysis & $19 \%$ & $7 \%$ & $74 \%$ \\
Use of probiotics in UC & $37 \%$ & $41 \%$ & $22 \%$ \\
Use of antibiotics in CD & $15 \%$ & $41 \%$ & $44 \%$ \\
$\begin{array}{l}\text { Follow-up by specialist in } \\
\text { relapsed patients }\end{array}$ & $85 \%$ & $15 \%$ & $0 \%$ \\
$\begin{array}{l}\text { Change of treatment with } \\
\text { specialist's advice }\end{array}$ & $85 \%$ & $15 \%$ & $0 \%$ \\
\hline
\end{tabular}

Abbreviations: UC, ulcerative colitis; CD, Crohn's disease.

GPs replied "No". Asked when they requested endoscopic followups (excluding patients with cancer), $41 \%$ said they did so when the disease relapsed, $29 \%$ said every two years, and $26 \%$ said once a year; the other $4 \%$ said they did so only rarely. Item 8 in Table 1 is basically to double-check of Item 7 , because variations in therapy often occurred when the disease relapsed. The data for Items 7 and 8 in Table 1 are equivalent.

Results of the satisfaction questionnaire following the course indicated that the course was successful in providing information to GPs (Table 3). For the following year (2008) we verified that regional hospitals had fairly analogous rates for CD (6.3/100,000 population/year; 95\% CI: 5.1-7.5) and for UC (18.9/100,000 population/year; 95\% CI: 16.7-21.1) to those in the period 2004-2006. Hospitalization rates in the Camerino-Matelica area were reduced compared with those of previous years but the confidence intervals require confirmation (for CD 4.1/100,000 population/year with 95\% CI: 0-9.8 and for UC 10.2/100,000 population/year with $95 \%$ CI: $1.3-19.1)$.

\section{Discussion}

To the best of our knowledge, the present study is the first in Italy to focus on how GPs approach the problem of IBD, and it probably reflects the situation in other parts of Central Italy too. A weakness of our questionnaire is its generic nature, but considering the small numbers of IBD patients followed

Table 3 Results of satisfaction questionnaire

\begin{tabular}{ll}
\hline Questions & Mean \pm SD \\
\hline $\begin{array}{l}\text { How much did the educational course influence } \\
\text { your knowledge of IBD? }\end{array}$ & $4.2 \pm 0.8$ \\
How much will the course affect your clinical practice? & $3.9 \pm 0.9$ \\
$\begin{array}{l}\text { How interesting did the teachers succeed in making } \\
\text { the topics covered? }\end{array}$ & $4.0 \pm 0.9$ \\
\hline
\end{tabular}

Notes: Satisfaction range: $0-5$. 
up by our GPs (2.4 patients per GP), we opted not to request details about specific clinical situations.

Our results indicate that GPs in our area examine their IBD patients once every 3-6 months and prescribe laboratory tests every six months on average. It is important to emphasize that IBD diagnosis and followup must involve not just endoscopy but also several laboratory blood and fecal tests. Our study indicates that fecal calprotectin, a biochemical marker of inflammatory activity, is still not widely used by GPs, and nor are probiotics prescribed for UC, or antibiotics prescribed for $\mathrm{CD}$. In addition to being an excellent noninvasive method for monitoring IBD, calprotectin is also useful in screening for these diseases. ${ }^{11,12}$ Fewer endoscopies are needed if fecal calprotectin or lactoferrin are used to follow up patients, and an endoscopic protocol to screen for cancer risk is not needed until 8-10 years after the IBD is diagnosed.

Another interesting issue emerging from our study is that our group of GPs resort to specialists primarily when their patient's disease relapses, and they tend to adjust therapy in consultation with a specialist, probably only when the disease relapses. The limited use of probiotics in UC and antibiotics in CD by the GPs may in part be due to poor attention of specialists to these therapies. Williams et al showed that both patients and GPs appreciate having ready access to the advice of a specialist. ${ }^{13}$ All the GPs in the Williams study were following up at least five IBD patients (twice the number that our GPs had in their care), and both patients and GPs wanted to be able to contact a specialist easily. It is likely that this would apply to our GPs and patients too, in the light of responses to Items 7 and 8 in Table 1. Casellas et al administered a questionnaire to 393 Spanish IBD patients about the services they received and emphasized the importance of patients and their families being adequately informed about their condition. ${ }^{14}$ The study was limited by the fact that it was conducted in a university environment, but it found that $97.8 \%$ of the patients considered the information they received about their disease inadequate. The authors also emphasized that the best way to give patients information is by talking to them directly. This is especially important because IBD is often associated with depression and anxiety, in which case personal contact between patients and their health care professionals is essential. Although the number of patient hospitalizations and the number of consultations with their gastroenterologists do not seem to improve patient information flow, we do not know if outpatient contact with GPs can improve the level of a patient's knowledge and information about his/her condition. ${ }^{15,16}$ Undoubtedly, the fact that the patients in the present study did not have ready access to a psychologist is a severe handicap, resulting in patients making more use of the health system's resources and having a suboptimal quality of life. ${ }^{17}$

Since any given GP has very few IBD patients, it is important for them to receive information and training periodically from specialists. We believe that the two most important duties of a GP are to provide their patients with information (also with a view to improving patient adherence to prescribed treatments) and to guarantee basic management and rapid access to a specialist in the event of relapse. ${ }^{18}$ Basic management should also include monitoring of any adverse effects of prescribed drugs. In the case of IBD, underestimating such adverse effects puts patients at serious risk, not only of hematologic sequelae, but also of potential renal, hepatic, and pulmonary toxicity. ${ }^{19,20}$

Although often overlooked, the indirect economic costs of a disease are also very important. Stark et al found that the monthly cost of an outpatient with CD in Germany is $€ 1425$ and for one with UC it is $€ 1015 ; 64 \%$ of the CD-related costs are indirect (eg, sick leave, early retirement) compared with $54 \%$ for UC patients. ${ }^{21}$ These costs might increase with greater use of biologic therapies, but adequate studies are needed, because increasing the use of these treatments might mean fewer hospital stays and medical appointments, and better quality of life and fewer absences from work.

Another point to emphasize is that our GPs did not advise their female IBD patients of child-bearing age to avoid becoming pregnant, even though a recent meta-analysis shows that pregnant women with IBD have higher rates of premature births, low-birthweight infants, cesarean sections, and babies with congenital abnormalities than do non-IBD controls. ${ }^{22}$ Although the data available do not permit any correlation of such adverse events with the activity of the disease, there are sporadic reports of women being more likely to have premature and low-birthweight infants if they have conceived in an active phase of their disease. Important messages that a female patient of child-bearing age should receive is that she should conceive her child while the disease is quiescent, and that close cooperation is needed between her gastroenterologist and her obstetrician. The patient needs to be clearly informed about which therapies to continue and which to stop, and when these should be stopped (ie, during the period of attempting to conceive, the first trimester, and lactation).

Perhaps the most interesting finding of this study is that the hospitalization rate for IBD was markedly reduced during 2008 in the Camerino-Matelica area (-69\% for CD and $-57 \%$ for UC) while the regional rates remained about the same. 
Of course we cannot exclude the fact that this lower rate was compensated for by higher rates in other regional hospitals, but we think this improbable, given the information imparted to GPs about IBD.

In conclusion, although IBD are not as widespread as other chronic diseases, such as hypertension, the fact that the incidence of IBD peak in patients about 30 years of age means that they can be a heavy burden on the health care system due to the patient needing treatment for many years.

We feel that more attention paid to IBD patients by GPs would result in cost savings, taking into account the balance between the savings (fewer hospital stays, fewer days off work) and the added costs (more use of sometimes costly medicines, more contact with the specialist). In any case, the changes we advocate would certainly result in a better quality of life for patients, who would then be able to contribute more to their families and communities. It is therefore necessary to ensure a good understanding of IBD among all health care personnel in order to provide efficient service to patients, avoid wasting resources, and improve patient quality of life.

\section{Acknowledgments}

The authors thank Professor GC Sturniolo, Director of the Gastroenterological Department, Padua University for reviewing the article and Dr R Amici, Health Planning - Marche Region for advice on this article.

\section{Disclosures}

The authors report no conflict of interest in this work.

\section{References}

1. Garcia Rodriguez LA, Gozalez-Perez A, Johansson S, et al. Risks factors for inflammatory bowel disease in the general population. Aliment Pharmacol Ther. 2005;22:309-315.

2. Ekbom A. The changing faces of Crohn's disease and ulcerative colitis. In: Targan SR, Shanahan F, Karp LC, editors. Inflammatory Bowel Disease. From Bench to Bedside. New York, NY: Springer Science; 2003. p. 5-20.

3. Ranzi T, Bodini P, Zambelli A, et al. Epidemiological aspects of inflammatory bowel disease in a north Italian population: A 4-year prospective study. Eur J Gastroenterol Hepatol. 1996;8:657-661.
4. Howarth GF, Robinson MHE, Jenkins D, et al. High prevalence of undetected ulcerative colitis: Data fom the Nottingham Fecal Occult Blood Screening Trial. Am J Gastroenterol. 2002;97:690-694.

5. http://www.amiciitalia.net/index.php?option=com_docman\&task= doc-download\&gid=131.

6. Rubin GP, Hungin APS, Kelly PJ, Ling J. Inflammatory bowel disease: Epidemiology and management in an English general practice population. Aliment Pharmacol Ther. 2000;14:1553-1559.

7. Numans ME. Chronic abdominal pain. In: Jones R, Britten N, Culpepper L, Gass D, Grol R, Mant D Silagy, editors. Oxford Textbook of Primary Medical Care. Oxford: Oxford University Press; 2005. p. 742-746.

8. Sands BE. Crohn's disease. In: Feldman M, Friedman LS, Brandt LJ, editors. Sleisenger and Fordtran's Gastrointestinal and Liver Disease. Philadelphia, PA: Saunders Elsevier; 2006. p. 2459-2498.

9. Rolland N, Grandbastien B, Merle V, et al. Coùt de la première prise en charge des maladies inflammatoires chronique de l'intestin. Gastroenterol Clin Biol. 1999;23:483-488. French.

10. Stone MA, Mayberry JF, Baker R. Prevalence and management of inflammatory bowel disease: A cross-sectional study from central England. Eur J Gastroenterol Hepatol. 2003;15:1275-1280.

11. Konikoff MR, Denson LA. Role of the calprotectin as a biomarker of intestinal inflammation in inflammatory bowel disease. Inflamm Bowel Dis. 2006;12:524-534.

12. D'Incà R, Dal Pont E, Di Leo V, et al. Can calprotectin predict relapse risk in inflammatory bowel disease? Am J Gastroenterol. 2008;103:2007-2014.

13. Williams JG, Cheung WY, Russel IT, et al. Open access follow up for inflammatory bowel disease: Pragmatic randomised trial and cost effectiveness study. Br Med J. 2000;320:544-548.

14. Casellas F, Fontanet G, Borruel N, et al. The opinion of patients with inflammatory bowel disease on healthcare received. Rev Esp Enferm Dig. 2004;96:174-184.

15. Drossmann DA, Ringel Y. Psychosocial factors in ulcerative colitis and Crohn's disease. In: Sartor RB, Sandborn WJ, editors. Kirsner's Inflammatory Bowel Diseases. Edinburgh: Saunders; 2004. p. 340-356.

16. Martinato M, Ferrante M, Burattin B, et al. Understanding of disease in patients with a recent diagnosis of inflammatory bowel disease. Journal of Crohn's and Colitis Suppl. 2008;2:45.

17. de Boer AG, Sprangers MA, Barrtelsman JF, et al. Predictors of health care utilization in patients with inflammatory bowel disease: A longitudinal study. Eur J Gastroenterol Hepatol 1998;10:783-789.

18. D'Incà R, Bertomoro $\mathrm{P}$, Mazzocco K, Vettorato MG, Rumiati R, Sturniolo GC. Risk factors for non-adherence to medication in inflammatory bowel disease patients. Aliment Pharmacol Ther. 2008;27:166-172.

19. Cunliffe RN, Scott BB. Review article: Monitoring for drug side-effects in inflammatory bowel disease. Aliment Pharmacol Ther. 2002;16: 647-662.

20. Sossai P, Cappellato MG, Stefani S. Can a drug-induced hypersensitivity reaction be dose-dependent? A case with mesalamine. Mt Sinai J Med. 2001;68:389-395.

21. Stark R, Konig HH, Leidl R. Costs of inflammatory bowel disease in Germany. Pharmacoeconomics. 2006;24:797-814.

22. Cornish J, Tan E, Teare J, et al. A meta-analysis on the influence of inflammatory bowel disease on pregnancy. Gut. 2007;56:830-837.
Clinical and Experimental Gastroenterology

\section{Publish your work in this journal}

Clinical and Experimental Gastroenterology is an international, peerreviewed, open access journal, publishing all aspects of gastroenterology in the clinic and laboratory, including: Pathology, pathophysiology of gastrointestinal disease; Investigation and treatment of gastoin testinal disease; Pharmacology of drugs used in the alimentary tract;

\section{Dovepress}

Immunology/genetics/genomics related to gastrointestinal disease. This journal is indexed on CAS. The manuscript management system is completely online and includes a very quick and fair peer-review system. Visit http://www.dovepress.com/testimonials.php to read real quotes from published authors. 